\title{
Gray matter-related proteins are associated with childhood-onset multiple sclerosis
}

\section{OPEN}

Vaibhav Singh, MSc

E. Daniëlle van Pelt, MD

Marcel P. Stoop, PhD

Christoph Stingl, DI (FH)

Immy A. Ketelslegers,

$\mathrm{MD}, \mathrm{PhD}$

Rinze F. Neuteboom,

$\mathrm{MD}, \mathrm{PhD}$

Coriene E. Catsman-

Berrevoets, MD, PhD

Theo M. Luider, $\mathrm{PhD}$

Rogier Q. Hintzen, MD, $\mathrm{PhD}$

Correspondence to

Dr. Hintzen:

r.hintzen@erasmusmc.nl

Supplemental data at Neurology.org/nn

\section{ABSTRACT}

Objective: To identify CSF biomarkers for multiple sclerosis (MS) in children with an initial acquired CNS demyelinating syndrome (ADS).

Methods: CSF was collected from a cohort of 39 children with initial ADS, 18 of whom were diagnosed with MS and 21 of whom had a monophasic disease course. Proteomic analysis of trypsinized CSF (20 $\mu \mathrm{L})$ was performed by nano-liquid chromatography Orbitrap mass spectrometry. Univariate statistical analysis was used to identify differentially abundant proteins between childhood-onset MS and monophasic ADS.

Results: A total of 2,260 peptides corresponding to 318 proteins were identified in the total set of samples. Of these 2,260 peptides, 88 were identified as being most distinctive between MS and ADS. Fifty-three peptides, corresponding to 14 proteins, had higher abundance in children with MS compared to children with monophasic ADS. Twelve of these 14 proteins were linked to neuronal functions and structures, such as synapses, axons, and CNS proteases (e.g., neurofascin, carboxypeptidase E, brevican core protein, and contactin-2). The other 2 were functionally related to immune function. The 35 peptides identified with decreased abundance in children with MS corresponded to 7 proteins. Six of them were linked to innate immune function (e.g., haptoglobin, haptoglobin-related protein, C4b-binding protein alpha chain, and monocyte differentiation antigen CD14) and 1 was linked to cellular adhesion (protein diaphanous homolog 1).

Conclusion: At first onset of ADS, CSF of children diagnosed with MS showed increased abundance of CNS gray matter-related proteins, whereas CSF of children with a monophasic disease course showed increased abundance of innate immunity-related proteins. Neurol Neuroimmunol Neuroinflamm 2015;2:e155; doi: 10.1212/NXI.0000000000000155

\section{GLOSSARY}

ADS = acquired demyelinating syndrome; ADEM = acute disseminated encephalomyelitis; CIS = clinically isolated syndrome; LC-MS = nano-liquid chromatography Orbitrap mass spectrometry; $\mathbf{M S}=$ multiple sclerosis; $\mathbf{N M O}=$ neuromyelitis optica; $\mathbf{O N}$ = optic neuritis; $\mathbf{R R M S ~ = ~ r e l a p s i n g ~ r e m i t t i n g ~} \mathrm{MS} ; \mathbf{T M}=$ transverse myelitis.

A few percent of all patients with multiple sclerosis (MS) experience their first event in childhood. ${ }^{1}$ In children, such a first event can present with a spectrum of clinical features of acquired demyelinating syndrome (ADS), including optic neuritis (ON), transverse myelitis (TM), acute disseminated encephalomyelitis (ADEM), neuromyelitis optica (NMO), and other clinically monofocal or polyfocal symptoms. ${ }^{2}$ In most children with ADS, the disease course remains monophasic. However, approximately $21 \%-32 \%$ of these children will subsequently be diagnosed with MS., ${ }^{3,4}$ Current MS diagnosis is based on a combination of clinical features, CSF findings, and MRI criteria for dissemination in time and space. ${ }^{1,3,5}$ These factors are insufficient to predict the disease course at first event. A biomarker that helps to differentiate between children with monophasic ADS and those subsequently diagnosed with MS is needed. Moreover, identification of CSF proteins that are associated with childhood-onset MS can provide further insight into the disease pathophysiology. So far, 1 study has compared the CSF of children with MS and

From the MS Centre ErasMS, Department of Neurology, Erasmus MC, Rotterdam, the Netherlands.

Funding information and disclosures are provided at the end of the article. Go to Neurology.org/nn for full disclosure forms. The Article Processing Charge was paid by the authors.

This is an open access article distributed under the terms of the Creative Commons Attribution-NonCommercial-NoDerivatives License 4.0 (CC BY-NC-ND), which permits downloading and sharing the work provided it is properly cited. The work cannot be changed in any way or used commercially. 
monophasic ADS, and this study suggested disturbed axoglial biology during early MS events. ${ }^{6}$ In the present study, we investigated CSF, a body fluid that reflects ongoing CNS pathology ${ }^{7}$ in a fully unbiased manner. Samples were analyzed by high-resolution sensitive nano-liquid chromatography Orbitrap mass spectrometry (LC-MS). ${ }^{8}$ Our aim was to find CSF protein markers expressed during a first event of CNS demyelination that can help to distinguish children with monophasic ADS $(\mathrm{n}=21)$ from children with MS $(\mathrm{n}=18)$.

METHODS Patients. Children younger than 18 years old who presented with a first acquired demyelinating event were identified by the Dutch Study Group for Pediatric MS, which includes 13 major pediatric neurology centers in the Netherlands, as described earlier. ${ }^{9}$ Children were diagnosed with MS if they had a second demyelinating attack of the CNS and/or MRI evidence of a new lesion at least 1 month after onset. ${ }^{1}$ Clinical features and physical examination defined initial clinical phenotypes of the children. This study included 41 children with ADS, 22 of whom had a monophasic disease course and 19 of whom were diagnosed with MS. The CSF samples were collected at first clinical presentation. Children were symptomatic at the time of sampling. Children were not on immunomodulatory treatment at the time of sampling. CSF samples were collected, processed, and stored following previously described protocols. ${ }^{8,10}$

Standard protocol approvals, registrations, and patient consents. The study was approved by the Clinical Research Ethics Board of Erasmus University. Written informed consent was obtained from all patients and/or their families.

Sample preparation and LC-MS measurements. CSF samples $(20 \mu \mathrm{L})$ were digested using an in-solution trypsin digestion protocol, as previously described. ${ }^{11}$ Prepared samples were analyzed by LC-MS/MS using an Ultimate 3000 nano RSLC system (Thermo Fischer Scientific, Germering, Germany) online coupled to a hybrid linear ion trap/Orbitrap mass spectrometer (LTQ Orbitrap XL; Thermo Fisher Scientific, Bremen, Germany) using a data-dependent acquisition method. LC-MS data were analyzed using the Progenesis LC-MS software package (version 3.6; Nonlinear Dynamics Ltd, Newcastle-uponTyne, United Kingdom). Detailed LC-MS measurements and protein identification and quantification information are available in the e-Methods at Neurology.org/nn.

Statistical analysis. The Wilcoxon test (unpaired, 2-tailed) was used to analyze the differences in the abundance of peptides between children with MS and those with monophasic ADS. $p$ values $<0.01$ were considered statistically significant. Relative quantitative differences of peptide abundances between samples of children with MS and samples of children with monophasic ADS were calculated as $\log _{2}$ ratio between median abundances of both groups. A set of significantly distinct peptides and proteins was determined by applying the following stringent criteria: (1) peptides that had at least 1.5 -fold difference in expression at a $p$ value $<0.01$, (2) protein identified by at least 2 peptides, and (3) at least $40 \%$ differentially abundant peptides $(p<0.01)$ per protein, whereby peptides of a given protein were required to have representation in the same direction (increased or decreased abundance in MS). In the above dataset we also excluded those proteins that had only 1 peptide differentially abundant out of a total 2. To verify these findings and to determine the statistical background level, we performed a permutation analysis on the entire dataset (2,260 peptides) between samples of children with MS $(\mathrm{n}=18)$ and samples of children with monophasic ADS $(n=21)$ included with the abovementioned criteria. Through this process, we determined the statistical background level on a set of significantly distinct peptides. The random permutation test was repeated 1,000 times on the dataset with randomized sample group assignment, and the resulting thresholds were saved. We used the $\mathrm{R}$ software package for all calculations and graphics ( $\mathrm{R}$ version 3.0.2). ${ }^{12}$ For other calculations we used SPSS 15.0 (SPSS, Chicago, IL) and Microsoft Excel 2010.

RESULTS Patient characteristics. We analyzed CSF samples of 18 children with MS and 21 with monophasic ADS. One patient with MS and 1 patient with monophasic ADS were excluded because $<200$ required alignment vectors (weak alignment) were found during Progenesis LC-MS analysis. Of the 18 children diagnosed with MS, 5 had ON, 2 had TM, 3 had clinical monofocal symptoms, and 8 had clinical polyfocal symptoms as their presenting symptoms at onset. Of the 21 children with monophasic ADS, 2 had ON, 2 had TM, 8 had clinical polyfocal symptoms, and 9 had ADEM as their presenting symptoms at onset. No significant differences were observed between the 2 groups in terms of sex, CSF levels of total protein and albumin, albumin CSF/ serum quotient, CSF leukocyte count, and CSF IgG concentration. The mean age at onset of children diagnosed with MS (14.17 \pm 1.5 years) was found to be significantly higher than that of children with monophasic ADS (6.89 \pm 4.9 years), reflecting the epidemiology of these phenotypes. In addition, elevated CSF IgG index and positive oligoclonal bands were more frequent in children with MS $(p \leq 0.01)$. Patient characteristics are shown in table 1 .

Identification of proteins that discriminate MS from monophasic ADS. We detected 50,119 peptide precursors from Progenesis label-free analysis LC-MS experiment from all trypsin-digested protein in CSF samples. A Mascot database search in the human subset of the Uniprot database resulted into 2,260 unique peptides that corresponded to 318 proteins (table e-1). The total protein concentrations of digested peptide samples quantified (integrated UV area at $214 \mathrm{~nm}$ ) during LC-MS measurements did not show any significant difference $(p=0.54)$ between CSF samples of children with MS and those of children with monophasic ADS. To check technical variability, we measured 12 reference samples (pooled CSF samples from all patients) at regular intervals. Here too the total protein concentrations of digested peptide samples quantified (integrated UV 
Table 1 Clinical characteristics of children with multiple sclerosis and monophasic acquired demyelinating syndrome

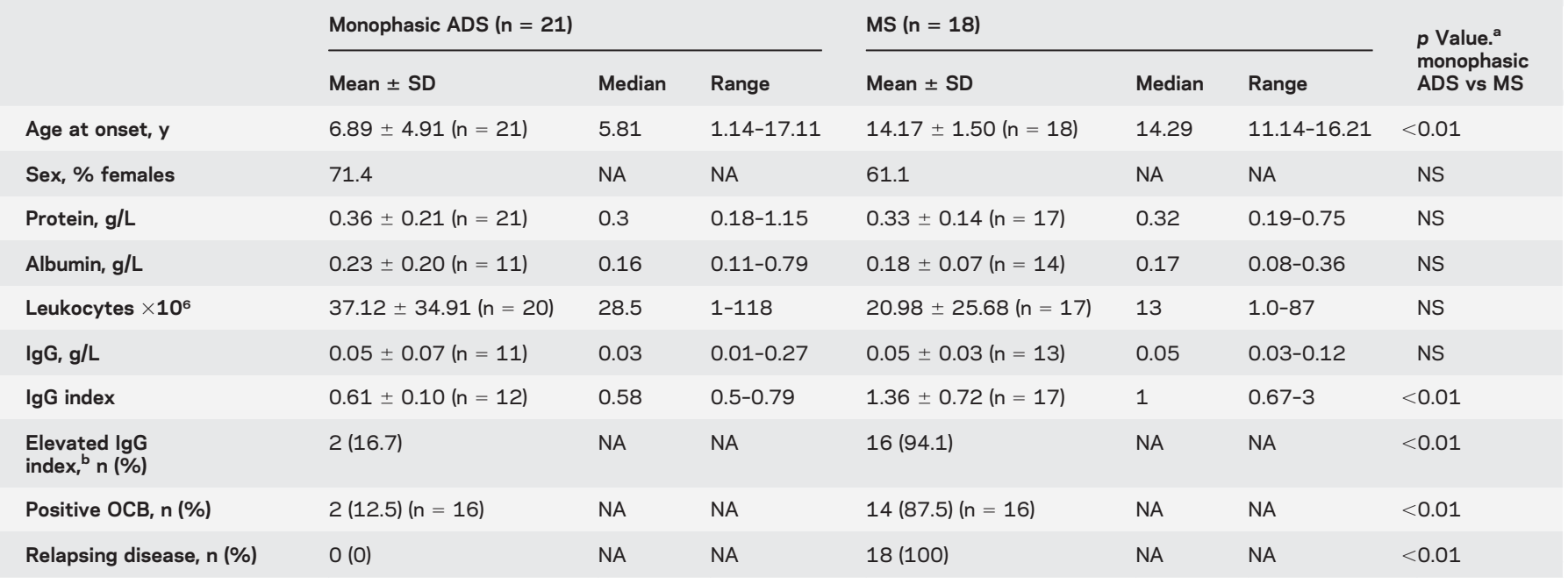

Abbreviations: ADS = acquired demyelinating syndrome; $M S$ = multiple sclerosis; NA = not applicable; NS = not significant; OCB = oligoclonal bands. This table shows clinical characteristics and routine CSF findings of children with MS (at disease onset) and children with monophasic ADS. Data are presented as the mean \pm SD or median and range. In case of missing data, the number of patients with available data is indicated in parentheses.

${ }^{a}$ Calculated by Mann-Whitney test and $p<0.01$ was considered significant.

${ }^{\mathrm{b}} \mathrm{lgG}$ index considered elevated at 0.68 or higher. ${ }^{4}$

area at $214 \mathrm{~nm}$ ) during LC-MS measurements did not show any difference between reference group $1(n=6)$ and reference group $2(n=6)$ (reference group 1: $382.94 \pm 153.28$; reference group 2: $429.34 \pm$ 661.90, $p=0.3$ ). In addition, a number of MS/MS fragmentation spectra did not show any significant difference between samples of children with MS and those of children with monophasic ADS. In particular, the measured MS/MS fragmentation spectra for MS and monophasic ADS samples were 16,796 \pm 1,795 and $16,971 \pm 1,153(p=0.72)$, respectively. Moreover, the database identified MS/MS spectra for MS and monophasic ADS samples as 1,607 \pm 280 and 1,626 $\pm 256(p=0.83)$, respectively.

Comparing the abundance of identified peptides ( $n=2,260)$ from CSF samples of children with MS and children with monophasic ADS using the stringent criteria described in the statistical analysis, we found a total of 88 differentially abundant peptides (tables e- 2 and e- 3 ). Of these 88 peptides, 53 were significantly increased (table 2 and table e-2) and 35 significantly decreased in CSF samples of children with MS (table 2 and table e-3) compared with samples of children with monophasic ADS. Peptides with increased abundance $(\mathrm{n}=53)$ in the MS group corresponded to 14 proteins and peptides with decreased abundance $(\mathrm{n}=35)$ corresponded to 7 proteins. An inventory of these 21 proteins is given in table 2 . Moreover, fold expression difference between the MS and monophasic ADS groups and statistical significance are plotted simultaneously for our entire dataset ( $n=2,260$ peptides) as a volcano plot (figure 1 ). This permutation analysis resulted in $20 \pm 41$ (median 9) false-positive peptide markers, which indicated that our observations are not due to chance alone, because more than $90 \%$ of the permutations yielded $0-4$ significant hits (i.e., in 900). Only 4 times out of 1,000 were more than 88 hits with low $p$ value detected (false discovery rate $0.4 \%$ ). Contrasting this to mere background chance, 88 peptides (true hits) were identified from the actual dataset. Therefore, comparison of permutated data with the real data indicated that the occurrence of differentially abundant peptides related to MS or monophasic ADS was highly significant $(p<$ $0.001)$. The outcome of the permutation test is shown as a histogram (figure e-1).

Identified proteins with increased abundance $(\mathrm{n}=14)$ in MS (table 2 and table e-2) were the following: amyloid-like protein 2 (2/2, 2 significant peptides for a total of 2 peptides), neurofascin (3/3), carboxypeptidase E (2/3), neuronal growth regulator 1 (2/3), contactin-2 (4/9), amyloid beta A4 (6/11), brevican core protein $(5 / 7)$, disintegrin and metalloproteinase domain-containing protein $22(2 / 2)$, tyrosineprotein phosphatase non-receptor type substrate 1 (3/4), dickkopf-related protein $3(6 / 11)$, neuronal cell adhesion molecule (9/18), Ig kappa chain V-III region POM (2/2), Ig gamma-1 chain $\mathrm{C}$ region (5/11), and kallikrein-6 (4/7). Proteins identified with decreased abundance $(\mathrm{n}=7)$ in MS (table 2 and table e-3) were the following: apolipoprotein B-100 (7/17), C4b-binding protein alpha chain (2/4), haptoglobin (18/29), haptoglobin-related protein (2/4), leucine-rich alpha-2-glycoprotein (2/3), monocyte differentiation antigen $\operatorname{CD} 14$ (3/3), and protein diaphanous homolog $1(2 / 2)$. The function of 


\begin{tabular}{|c|c|c|c|c|}
\hline \multicolumn{5}{|c|}{$\begin{array}{l}\text { Identification of proteins differentially abundant in CSF samples of children with MS }(n=18) \text { and } \\
\text { samples of children with monophasic ADS }(n=21)\end{array}$} \\
\hline Trend in $\mathrm{MS}^{\mathrm{a}}$ & Description & $\begin{array}{l}\text { Sign.l } \\
\text { total }^{b}\end{array}$ & $\begin{array}{l}\text { Fold change } \\
\text { mean (min-max) }\end{array}$ & $p$ Value $^{d}$ mean (min-max) \\
\hline \multirow{14}{*}{$\begin{array}{l}\text { Increased abundance } \\
\text { in MS }(n=14)\end{array}$} & Amyloid-like protein 2 & $2 / 2$ & $3.8(2-5.5)$ & $0.006(0.003-0.008)$ \\
\hline & Neurofascin & $3 / 3$ & $2.5(2.1-3)$ & $0.002(0.001-0.002)$ \\
\hline & Carboxypeptidase E & $2 / 3$ & $2.4(2.1-2.6)$ & $0.0004(0.0002-0.0005)$ \\
\hline & Neuronal growth regulator 1 & $2 / 3$ & $2.3(2.1-2.5)$ & $0.0008(0.0008-0.0009)$ \\
\hline & Contactin-2 & $4 / 9$ & $2.3(1.5-3.2)$ & $0.002(0.0005-0.003)$ \\
\hline & Amyloid beta $\mathrm{A} 4$ protein & $6 / 11$ & $2.2(1.8-2.6)$ & 0.002 (0.00003-0.008) \\
\hline & Brevican core protein & $5 / 7$ & $2.1(1.7-2.6)$ & $0.002(0.0001-0.005)$ \\
\hline & $\begin{array}{l}\text { Disintegrin and metalloproteinase } \\
\text { domain-containing protein } 22\end{array}$ & $2 / 2$ & $1.9(1.7-2.1)$ & $0.0004(0.0001-0.0006)$ \\
\hline & $\begin{array}{l}\text { Tyrosine-protein phosphatase } \\
\text { non-receptor type substrate } 1\end{array}$ & $3 / 4$ & $1.9(1.5-2.1)$ & $0.003(0.001-0.006)$ \\
\hline & Dickkopf-related protein 3 & $6 / 11$ & $1.8(1.6-2)$ & $0.002(0.00004-0.006)$ \\
\hline & Neuronal cell adhesion molecule & $9 / 18$ & $1.8(1.6-2.1)$ & 0.004 (0.001-0.009) \\
\hline & Ig kappa chain V-III region POM & $2 / 2$ & $1.8(1.7-1.8)$ & $0.002(0.0009-0.003)$ \\
\hline & Ig gamma- 1 chain $\mathrm{C}$ region & $5 / 11$ & $1.7(1.5-1.8)$ & $0.0016(0.0002-0.005)$ \\
\hline & Kallikrein-6 & $4 / 7$ & $1.7(1.5-1.9)$ & $0.001(0.0006-0.004)$ \\
\hline \multirow{7}{*}{$\begin{array}{l}\text { Decreased abundance } \\
\text { in MS }(n=7)\end{array}$} & Apolipoprotein B-100 & $7 / 17$ & $661(3.5-3,930)$ & $0.0026(0.00002-0.01)$ \\
\hline & C4b-binding protein alpha chain & $2 / 4$ & $8.1(2.9-13.4)$ & $0.008(0.007-0.008)$ \\
\hline & Haptoglobin & $18 / 29$ & $3.7(2-12.1)$ & $0.002(0.00004-0.01)$ \\
\hline & Haptoglobin-related protein & $2 / 4$ & $3.3(3.1-3.5)$ & $0.0002(0.00001-0.0005)$ \\
\hline & Leucine-rich alpha-2-glycoprotein & $2 / 3$ & $2.6(2.3-3)$ & $0.008(0.007-0.009)$ \\
\hline & Monocyte differentiation antigen CD14 & $3 / 3$ & $1.9(1.8-2)$ & $0.006(0.004-0.009)$ \\
\hline & Protein diaphanous homolog 1 & $2 / 2$ & $1.8(1.7-1.9)$ & 0.005 (0.001-0.009) \\
\hline
\end{tabular}

Abbreviations: $A D S=$ acquired demyelinating syndrome; $M S=$ multiple sclerosis.

The table shows 21 proteins, of which 14 were identified with increased abundance in CSF samples of children with MS and 7 were identified with decreased abundance in CSF samples of children with MS. The table includes the direction of difference (trend) in MS, name of the protein (description), fold expression difference, and $p$ value. All proteins given in the table were identified with at least 2 unique peptides; differentially abundant peptides $(p<0.01)$ had at least 1.5 -fold difference in expression (median) between groups; and for the same protein, $40 \%$ of identified peptides were differentially abundant with the expression in the same direction (i.e., either higher or lower in MS) of the same protein. Details of each peptide of the indicated proteins are listed in tables e-2 and e-3.

a Protein abundance is either significantly increased or decreased in children with MS compared to children with monophasic ADS.

${ }^{b}$ Number of differentially identified peptides $p<0.01 /$ total number of identified peptides for the same protein.

${ }^{c}$ Fold expression difference calculated based on median abundance from 18 patients with MS and 21 patients with ADS. Shown is the average of fold difference for all peptides of the same protein. Minimum and maximum range for the same is indicated.

${ }^{d}$ Calculated by Wilcoxon test. Given in the table is the mean $p$ value and range for all differentially abundant peptides of the same protein.

these 14 proteins and overlap with previous studies ${ }^{6,13}$ are summarized in table 3 . Among the 14 proteins with increased abundance in MS, 12 were associated with CNS structure and functions (86\%), especially the gray matter (table 3 ), whereas only $17 \%$ of the total identified proteins were related to CNS structure and functions. The 7 proteins with decreased abundance in MS (relative to the monophasic ADS group) were components of the innate immune system and inflammation (table 4).
For each peptide that passed (53 increased and 35 decreased in MS) all stringent criteria (described in the statistical analysis), the associated protein, database search identification details, $p$ value, fold expression difference, total number of peptides per protein, number of peptides identified below 0.01 , median abundance, and frequency/occurrence of identifications by MS/MS spectra are shown in tables e-2 and e-3. Proteins identified in the current study did not exhibit any myelin-related proteins (e.g., myelin 
Figure 1 Volcano plot

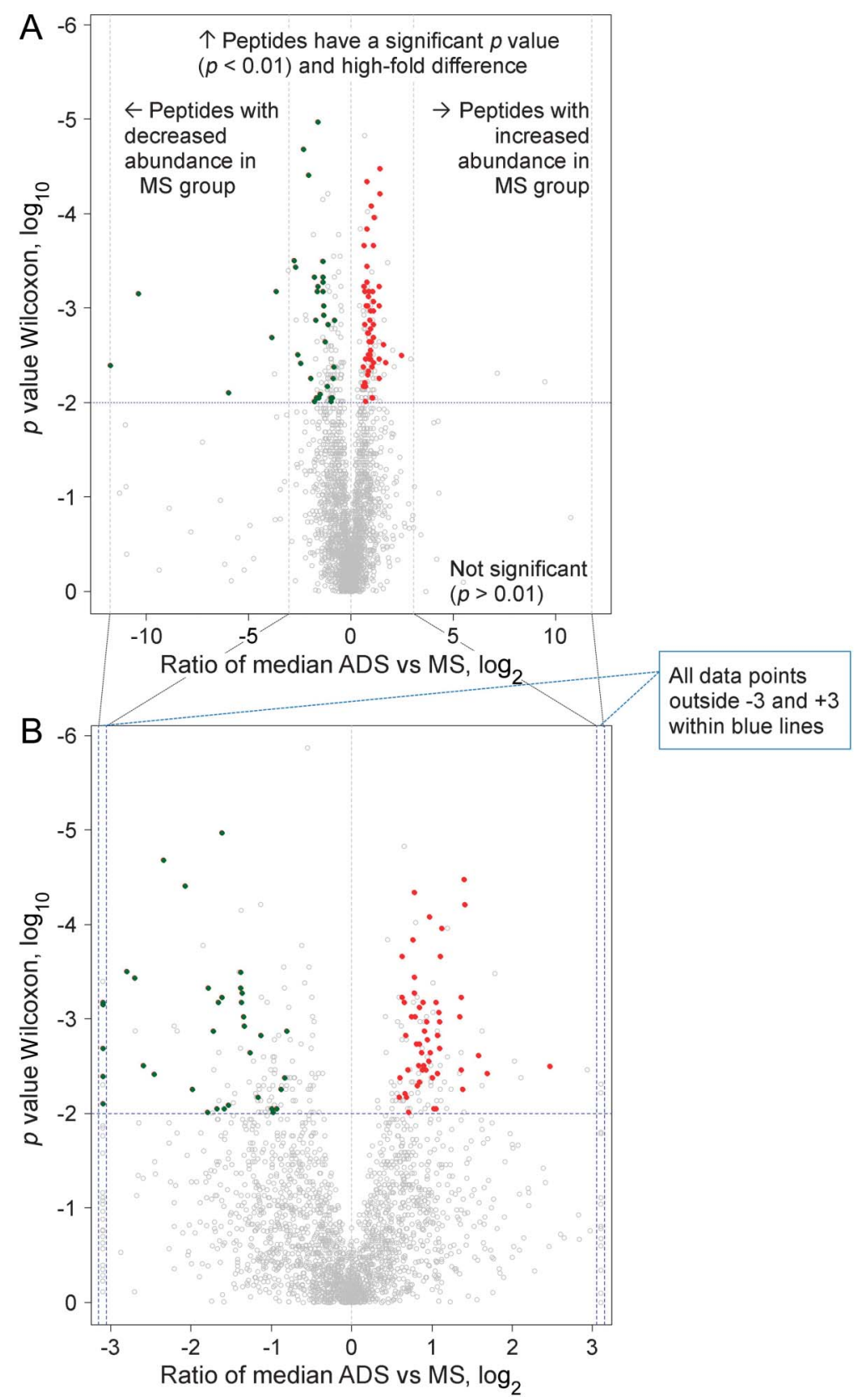

Peptides ( $n=2,260$ ) showing distribution of fold change and statistical significance. In this plot, each point represents a peptide and shows the ratio between CSF samples of children with multiple sclerosis (MS) $(n=18)$ and samples of children with monophasic acquire demyelinating syndromes (ADS) $(n=21)$ plotted against the level of statistical significance. Y-axis shows $p$ values obtained (plotted at $\log _{10}$ ) from a Wilcoxon test performed between abundances of peptides. $X$-axis shows the ratio of the median between MS and monophasic ADS samples (plotted on $\log _{2}$ ). (A) Above the dashed horizontal line, red points ( $n=53$ peptides) were found with increased abundance (right side of the vertical line) and green points ( $n=35$ peptides) with decreased abundance (left side of the vertical line) in the MS group (compared to the monophasic ADS group). (B) Peptides shown in gray below the dashed horizontal line did not pass the stringent statistical criteria for identification of a candidate peptide.

oligodendrocyte glycoprotein and myelin basic protein).

We performed a correlation analysis to examine the influence of age at onset on the abundance of the 88 candidate peptides in children with MS and monophasic ADS. We found a mean coefficient of determination $( \pm S D)$ of $0.04 \pm 0.06$ for MS and $0.05 \pm 0.05$ for monophasic ADS. Thus, no significant correlation was found between age and peptide abundance for children with MS and monophasic ADS for all 88 peptides.

DISCUSSION In the current study, we used a LCMS proteomic approach to search for differences in CSF proteome between children with MS and children with monophasic ADS. A benefit of this Orbitrap technique is the ability to identify relatively vast amounts of different peptides and assess their abundances in a small sample volume. We observed a striking difference between the 2 groups (children with monophasic ADS vs MS) using stringent statistical criteria. We searched for the known functions of the 88 peptides corresponding to 21 distinctive proteins (14 increased and 7 decreased in abundance in MS) using biological databases (www.geneontology.org and www.nextprot. org) and literature. Recently, 2 research groups ${ }^{6,13}$ demonstrated the identification of axoglial and gray matter proteins using mass spectrometry in CSF of patients with MS. Similar to our study, Dhaunchak et al. ${ }^{6}$ compared CSF of 8 children with MS with CSF of 11 children with monophasic ADS. The overlap of some proteins in the MS group is noticeable (e.g., carboxypeptidase E), despite clear differences in sample handling, such as depletion of abundant proteins with possible carrier function for other proteins and exclusion of proteins with less than $5 \mathrm{kDa}$ weight (table 3).

Our results show overlap with molecules identified in the CSF of adults with acute-onset MS by Schutzer et al., ${ }^{13}$ who performed mass spectrometry analysis in CSF of patients with clinically isolated syndrome (CIS) vs those with established relapsing remitting MS (RRMS) and controls (table 3). They found proteins that distinguished patients with CIS from both patients with established RRMS and controls. For example, they found a significant increase in kallikrein-6 and dickkopf-related protein 3 at first clinical onset compared to patients with established RRMS and controls (table 3). They also found a significant increase in contactin-2 (neuronal membrane protein) in patients with a first attack of MS relative to those with established RRMS (table 3 ). ${ }^{13}$

Our findings illustrate that the neurodegenerative arm of MS neuropathology is already active at the earliest stage of clinical disease, also in children. Consistent with the findings of others and our own previous studies, ${ }^{6,14-16}$ we again observed a striking lack of myelin proteins in these clear-cut cases of acute demyelination. This may not directly imply absence of such free proteins in this type of pathology, but rather 
Table 3 Function of proteins identified with increased abundance in CSF samples of children with MS compared with samples of children with monophasic ADS

Protein (accession no.)

Amyloid-like protein 2 (Q06481)

Neurofascin (094856)

Contactin-2 (Q02246)

Amyloid beta A4 protein (P05067)

Brevican core protein (Q96GW7)

Carboxypeptidase E (P16870)

Neuronal growth regulator

1 (Q7Z3B1)

Tyrosine-protein phosphatase nonreceptor type substrate 1 (P78324)

Neuronal cell adhesion molecule (Q92823)

Disintegrin and metalloproteinase domain-containing protein 22 (Q9P0K1)

Dickkopf-related protein 3 (Q9UBP4)

Kallikrein-6 (Q92876)

Ig gamma-1 chain C region (P01857)

\section{Ig kappa chain $\mathrm{V}$-III region POM} (P01624)

\section{Functions and expressions}

Amyloid precursor protein family, memory processes, concentrated in synapses, ${ }^{18}$ regulates neuronal stem cell differentiation during cortical development

Synapse formation, located at CNS paranodal domain and expressed by oligodendrocytes, ${ }^{20}$ target for autoantibody-mediated axonal injury in $\mathrm{MS}^{21}$

Axon connection, majorly expressed on CNS juxtaparanodal domain ${ }^{19,20}$

Component of amyloid plaques (Alzheimer brains), ${ }^{35}$ neuronal adhesion

Major proteoglycan in perisynaptic extracellular matrix of brain, inhibits neurite outgrowth from cerebellar granule neurons ${ }^{23}$

Found in brain and throughout neuroendocrine system, involved in synthesis of most neuropeptides ${ }^{36}$

Promotes outgrowth and is expressed on reactive astrocytes after entorhinal cortex lesion (in mice) ${ }^{37}$

Supports adhesion of cerebellar neurons, neurite outgrowth, and glial cell attachment ${ }^{28}$

Localized at the node of Ranvier and in unmyelinated axons, paranodal region of CNS, axoglial contact ${ }^{19}$

Expressed in the juxtaparanodal complex ${ }^{19}$

\section{Dhaunchak et al.}

Schutzer et al. ${ }^{13}$

** variant

NS

NS

$\times$

NS

Same trend ( 4 sign./

21 total; $p=0.004$ )

NS

NS

Not same trend ( 2 sign./ 10 total; $p=0.01,0.02)$

Expressed in the brain and spinal cord, synapse formation $^{13}$

Elevated in active $\mathrm{MS}^{26}$ regulates early CNS demyelination in a viral (mouse) model of $\mathrm{MS}^{26}$

Elevated in adult MS and CIS compared to noninflammatory neurologic disease ${ }^{38}$

Elevated in adult MS compared to noninflammatory and inflammatory neurologic disease ${ }^{38}$ $\times \quad$ *

$\times$

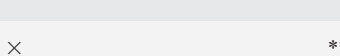

Abbreviations: $\mathrm{ADS}=$ acquired demyelinating syndrome; $\mathrm{CIS}=$ clinically isolated syndrome; $\mathrm{MS}=$ multiple sclerosis; $\mathrm{NS}=$ not significant; $\mathrm{RRMS}=$ relapsing remitting MS.

$\times=$ protein was not identified; ** variant $=$ variant of same protein was found with increased expression in first-attack CIS-MS group compared to established RRMS and controls; ** = increased expression in first-attack CIS-MS group compared to established RRMS and controls; *** = protein was found with increased expression in first-attack CIS-MS relative to RRMS but with decreased expression in first-attack CIS-MS vs controls; NS = protein was detected in pediatric CSF samples but no statistical difference in their abundance was reported between MS and monophasic ADS group comparison; same trend (trend is the direction of difference in MS) = when abundance of the protein was compared between 2 group (MS vs monophasic ADS), expression of the identified protein showed overlap with our study; not same trend = when abundance of protein was compared, expression of the identified protein did not show overlap with our study.

Nodes, paranodes, juxtaparanodes (begins at the innermost axoglia junction of paranode), and internodes are structural parts of a myelinated axon.

Summary of the function of differentially abundant increased protein markers in MS and their overlap with previous studies. Most of the proteins were assigned as either neuronal or immune-related molecules based on previous reports and database searches. The first column shows the name of the protein and Uniprot accession number. The second column shows the function of the proteins. The third column shows comparison with a previous study on children with MS (Dhaunchak et al.) using ADS-MS ( $n=8$, mean age 12 years) vs monophasic ADS ( $n=11$, mean age 10 years). The fourth column shows overlap with the work of Schutzer et al., who used CIS-MS ( $n=9$, age 18-42 years) and established MS and controls ( $n=6$, age 31-54 years).

it may reflect the specific physicochemical properties of the hydrophobic myelin components and perhaps different pathways of elimination from the CSF (e.g., via draining macrophages). ${ }^{17}$ In any case, we must be cautious in using the dominant presence of CNS gray matter over white matter proteins as proof that neurodegeneration is a primary event in MS and would precede demyelination. The presence of CNS gray matter may simply represent damage by inflammation, and the molecules identified may lead to a better understanding of this presumed inflammationinduced neurodegeneration. It should be stressed that not all differentially abundant proteins were overrepresented in MS; some were underrepresented, pointing at more complex mechanisms, such as a perturbation in the physiology of the axoglial apparatus (table 2 and tables e-2 and e-3). ${ }^{6}$ A confounding factor in our study could be the fact that the groups were not matched according to age because of the occurrence of monophasic disease at younger ages. 
Table 4 Function of proteins identified with decreased abundance in CSF samples of children with MS compared to samples of children with monophasic ADS

\begin{tabular}{|c|c|c|c|}
\hline Protein (accession no.) & Functions & $\begin{array}{l}\text { Dhaunchak } \\
\text { et al. }{ }^{6}\end{array}$ & $\begin{array}{l}\text { Schutzer } \\
\text { et al. }{ }^{13}\end{array}$ \\
\hline Apolipoprotein B-100 (P04114) & $\begin{array}{l}\text { Innate immune-related, not produced in } \\
\text { CNS }^{39}\end{array}$ & $x$ & $\times$ \\
\hline C4b-binding protein alpha chain (P04003) & $\begin{array}{l}\text { Innate immune defense, involved in } \\
\text { complement activity }{ }^{31}\end{array}$ & $\times$ & $\times$ \\
\hline Haptoglobin (P00738) & Innate immune defense ${ }^{29}$ & $\times$ & $\times$ \\
\hline Haptoglobin-related protein (P00739) & Innate immune defense ${ }^{40}$ & $\times$ & $\times$ \\
\hline Leucine-rich alpha-2-glycoprotein (P02750) & $\begin{array}{l}\text { Induced by inflammation and involved in } \\
\text { cell adhesion, high expression in the deep } \\
\text { cerebral cortex, }{ }^{25} \text { novel marker of } \\
\text { granulocytic differentiation }{ }^{29}\end{array}$ & $\times$ & $\times$ \\
\hline $\begin{array}{l}\text { Monocyte differentiation antigen CD14 } \\
\text { (P08571) }\end{array}$ & Main modulator of innate immune system ${ }^{32}$ & $\times$ & $\times$ \\
\hline Protein diaphanous homolog 1 (060610) & $\begin{array}{l}\text { Coordinates cellular dynamics by } \\
\text { regulating microfilament and microtubule } \\
\text { function, role in cell-matrix adhesions, } \\
\text { variant related to innate immune function }\end{array}$ & $\times$ & $\times$ \\
\hline
\end{tabular}

Abbreviations: ADS = acquired demyelinating syndrome; CIS = clinically isolated syndrome; MS = multiple sclerosis. $\times=$ Protein was not identified.

Summary of the function of differentially abundant decreased protein markers in MS and their overlap with previous studies. Most of the proteins were assigned as either neuronal or immune-related molecules based on previous reports and database searches. The first column shows the name of the protein and Uniprot accession number. The second column shows the function of the proteins. The third column shows comparison with a previous study on children with MS (Dhaunchak et al.) using ADS-MS ( $n=8$, mean age 12 years) vs monophasic ADS ( $n=11$, mean age 10 years). The fourth column shows overlap with the work of Schutzer et al., who used CIS-MS ( $n=9$, age 18-42 years) and established MS and controls ( $n=6$, age 31-54 years).

We doubt that this influenced the results, however, because we did not see an age effect on the abundance of the 21 identified proteins.

Of the 14 proteins with increased abundance in MS (tables 2 and 3), 2 were associated with the amyloid beta A4 protein family. Amyloid-like protein 2 is mainly concentrated at neuronal synapses ${ }^{18}$ and has a role in memory processes, whereas amyloid beta $\mathrm{A} 4$ protein is associated with neurite growth, neuronal adhesion, and axonogenesis (table 3). Six proteins (contactin-2, ${ }^{19}$ neurofascin, ${ }^{20}$ neuronal growth regulator 1 , brevican core protein, ${ }^{6}$ neuronal cell adhesion molecule, ${ }^{19}$ and disintegrin and metalloproteinase domain-containing protein 22) ${ }^{19}$ are located at the paranodal and juxtaparanodal region of the CNS of myelinated axons (table 3). Contactin-2 is an axonal glycoprotein at the juxtaparanodal domain of myelinated axons. ${ }^{13}$ Neurofascin plays a role in the assembly of nodes of Ranvier in the CNS. ${ }^{21}$ Two isoforms of neurofascin have been shown to interact with contactin-associated protein and contactin- 1 to form a paranodal junction that attaches the myelin loop to the axon and helps to separate voltage-gated sodium channels at nodal and potassium channels at juxtaparanodal regions. ${ }^{20}$ Disruption of neurofascin localization reveals early changes preceding demyelination and remyelination in MS. ${ }^{22}$ Of interest, contactin-2 and neurofascin have previously been reported as autoimmune targets in $\mathrm{MS}^{20}$ Neuronal growth regulator 1 is located at the paranodal region of the CNS and plays a role in axoglia contact at the node of Ranvier. Identification of contactin-2 and neurofascin in the CSF of children with MS is consistent with a previous study ${ }^{6}$; however, they did not find a significant difference in the CSF of children with MS and monophasic ADS (tables 2 and 3). Brevican core protein is known as a CNS-specific proteoglycan ${ }^{19}$ at the surface of neuroglial sheaths, where it is enriched in perisynaptic extracellular matrix. ${ }^{23}$

Among the 14 proteins with increased abundance in MS, the proteases/peptidases protein carboxypeptidase $\mathrm{E}$ plays a role in the synthesis of most neuropeptides. ${ }^{24}$ Disintegrin and metalloproteinase domain-containing protein 22 is highly expressed in the brain and localized at the juxtaparanode. ${ }^{19}$ This molecule is presumed to be a major neuronal receptor. ${ }^{25}$ Another brain-related protease is kallikrein-6, which is a secreted serine protease. ${ }^{13}$ It regulates early CNS demyelination in a viral model (expression in the brain and spinal cord of mice) of MS. ${ }^{26}$ In addition, elevated levels of kallikrein-6 in CSF have been reported in adults with MS compared to neurologic controls (table 3). ${ }^{27}$

Among the other proteins with increased abundance in MS, tyrosine-protein phosphatase nonreceptor type substrate 1 is implicated in neurite outgrowth and glia cell attachment and has been shown to support adhesions of cerebellar neurons. ${ }^{28}$ 
The highest expression of dickkopf-related protein 3 is reported in the brain and spinal cord (table 3). ${ }^{13}$ Thus, the majority of proteins with increased abundance in our MS group (compared to the monophasic ADS group) were neuronal-related, with the exception of 2 immune function-related proteins (Ig gamma-1 chain $\mathrm{C}$ region and Ig kappa chain V-III region POM) (table 3 ).

Our study reports 7 proteins with decreased abundance in pediatric-onset MS compared to monophasic ADS (table 2 and table e-3). Six of these 7 proteins have previously been reported as specific components of innate immune functions (table 4). Haptoglobin, an acute phase protein, ${ }^{29}$ was identified as the most distinctive protein of those that were elevated in children with monophasic ADS (compared to children with MS) (18/29, 18 significant peptides for a total of 29 peptides). Another study in adults showed increased haptoglobin concentration in patients with NMO compared to adult patients with MS. ${ }^{30} \mathrm{C} 4 \mathrm{~b}$ binding protein alpha chain is a crucial component of complement cascade and inhibits the function of complement component. ${ }^{31}$ Of interest, we also found monocyte differentiation antigen CD14, which is mainly expressed on cells of monocytic lineage (macrophages and monocytes). ${ }^{32}$ Higher CD14 levels might be linked with increased levels of cytokines, triggering inflammatory processes in children with monophasic ADS. Monocytic cells secrete soluble sCD14 (activation product of activated monocytes), so this may affect the enormous macrophage activation during acute monophasic ADS. ${ }^{33}$ Among the 7 identified proteins, protein diaphanous homolog 1 has a role in cell adhesion and is expressed in brain, and its variants are required for innate immune response to Gramnegative bacterial infection. ${ }^{34}$

Overall, in the MS group we found a significant overrepresentation of proteins associated with changes in CNS gray matter, axons, synaptic regulation, node of Ranvier, and brain proteases (table 3 ). Several of these proteins are part of the axoglial apparatus and may relate to disturbances in axoglia interaction $^{6}$ (table 3). Two of them (contactin-2 and neurofascin) have been identified as possible axoglial autoantigens in $\mathrm{MS}^{20}$ The overlap of proteins observed in previous studies ${ }^{6,13}$ (table 3 ) as part of the axoglia apparatus and gray matter provides validation for these proteins.

These pathologically relevant proteins (mostly CNS gray matter-related) that are elevated in the CSF of children with early-onset MS might be involved in early disease mechanisms. Further insight into the role of these proteins can be useful for understanding the disease process. Moreover, such proteins might be useful as a future tool to differentiate children with MS from children with monophasic ADS. In addition, knowing the start of MS could lead to earlier treatment with disease-modifying therapies. However, the current research is designated as a discovery phase study, which serves as a basis for the follow-up verification and validation phase studies that can provide clinically valuable biomarkers. In the future, it would be interesting to further validate our findings with an independent technology and in an independent sample group.

The data presented in this study indicate that monophasic ADS can be differentiated from MS in children primarily by CNS gray matter proteins and immune-related proteins. Our findings point to perturbed axoglial physiology as a hallmark of the earliest events of MS pathogenesis.

\section{AUTHOR CONTRIBUTIONS}

The work was carried out in collaboration among all authors. V.S., T.M.L., and R.Q.H. designed the experiment. V.S. and C.S. performed the experiment and statistical analysis. E.D.v.P., I.A.K., and C.E.C.-B. were responsible for sample collection. V.S., E.D.v.P., M.P.S., C.S., R.F.N., T.M.L., and R.Q.H. interpreted the results and wrote the article. All authors critically revised and approved the final manuscript.

\section{ACKNOWLEDGMENT}

The authors thank all the children and their families who participated in the Dutch Study for Pediatric MS.

\section{STUDY FUNDING}

This work was supported by a program grant provided by the EC 7th frame work programme of Marie Curie Initial Training Network-The United Europeans for the Development of Pharmacogenomics in Multiple Sclerosis (UEPHA-MS grant PITN_GA-2008212877), Netherlands Multiple Sclerosis Research Foundation to the Rotterdam MS Centre, ErasMS, the Netherlands Organization for Scientific Research (ZON-MW, RQH), and Hersenstichting Nederland and Zenith grant 93511034 from the Netherlands Organization for Scientific Research (NWO).

\section{DISCLOSURE}

V. Singh, E.D. van Pelt, M.P. Stoop, C. Stingl, and I.A. Ketelslegers report no disclosures. R.F. Neuteboom is on the scientific advisory board for LAREB. C.E. Catsman-Berrevoets and T.M. Luider report no disclosures. R.Q. Hintzen is on the advisory board for Biogen Idec, Roche, and Sanofi; received research support from Biogen Idec, Merck-Serono, Roche, Genzyme, Novartis, Dutch MS Society, and European Commission; and is on the editorial board for Multiple Sclerosis and Related Disorders. Go to Neurology.org/nn for full disclosure forms.

Received April 14, 2015. Accepted in final form June 25, 2015.

\section{REFERENCES}

1. Krupp LB, Banwell B, Tenembaum S; International Pediatric MSSG. Consensus definitions proposed for pediatric multiple sclerosis and related disorders. Neurology 2007; 68:S7-S12.

2. Banwell B, Ghezzi A, Bar-Or A, Mikaeloff Y, Tardieu M. Multiple sclerosis in children: clinical diagnosis, therapeutic strategies, and future directions. Lancet Neurol 2007;6: 887-902.

3. Banwell B, Bar-Or A, Arnold DL, et al. Clinical, environmental, and genetic determinants of multiple sclerosis in 
children with acute demyelination: a prospective national cohort study. Lancet Neurol 2011;10:436-445.

4. Neuteboom RF, Boon M, Catsman Berrevoets CE, et al. Prognostic factors after a first attack of inflammatory CNS demyelination in children. Neurology 2008;71:967-973.

5. Krupp LB, Tardieu M, Amato MP, et al. International Pediatric Multiple Sclerosis Study Group criteria for pediatric multiple sclerosis and immune-mediated central nervous system demyelinating disorders: revisions to the 2007 definitions. Mult Scler 2013;19:1261-1267.

6. Dhaunchak AS, Becker C, Schulman H, et al. Implication of perturbed axoglial apparatus in early pediatric multiple sclerosis. Ann Neurol 2012;71:601-613.

7. Singh V, Hintzen RQ, Luider TM, Stoop MP. Proteomics technologies for biomarker discovery in multiple sclerosis. J Neuroimmunol 2012;248:40-47.

8. Singh V, Stoop MP, Stingl C, et al. Cerebrospinal-fluidderived immunoglobulin $\mathrm{G}$ of different multiple sclerosis patients shares mutated sequences in complementarity determining regions. Mol Cell Proteomics 2013;12: 3924-3934.

9. Ketelslegers IA, Catsman-Berrevoets CE, Neuteboom RF, et al. Incidence of acquired demyelinating syndromes of the CNS in Dutch children: a nationwide study. J Neurol 2012;259:1929-1935.

10. Teunissen CE, Petzold A, Bennett JL, et al. A consensus protocol for the standardization of cerebrospinal fluid collection and biobanking. Neurology 2009;73:1914-1922.

11. Stoop MP, Singh V, Stingl C, et al. Effects of natalizumab treatment on the cerebrospinal fluid proteome of multiple sclerosis patients. J Proteome Res 2013;12:1101-1107.

12. Team RC. R: A Language and Environment for Statistical Computing [online]. Available at: http://www.R-project. org/. Accessed February 4, 2014.

13. Schutzer SE, Angel TE, Liu T, et al. Gray matter is targeted in first-attack multiple sclerosis. PLoS One 2013;8: e66117.

14. Stoop MP, Dekker LJ, Titulaer MK, et al. Multiple sclerosis-related proteins identified in cerebrospinal fluid by advanced mass spectrometry. Proteomics 2008;8: 1576-1585.

15. Stoop MP, Dekker LJ, Titulaer MK, et al. Quantitative matrix-assisted laser desorption ionization-fourier transform ion cyclotron resonance (MALDI-FT-ICR) peptide profiling and identification of multiple-sclerosis-related proteins. J Proteome Res 2009;8:1404-1414.

16. Stoop MP, Singh V, Dekker LJ, et al. Proteomics comparison of cerebrospinal fluid of relapsing remitting and primary progressive multiple sclerosis. PLoS One 2010;5: e12442.

17. van Zwam M, Samsom JN, Nieuwenhuis EE, et al. Myelin ingestion alters macrophage antigen-presenting function in vitro and in vivo. J Leukoc Biol 2011;90:123-132.

18. Wasco W, Gurubhagavatula S, Paradis MD, et al. Isolation and characterization of APLP2 encoding a homologue of the Alzheimer's associated amyloid beta protein precursor. Nat Genet 1993;5:95-100.

19. Faivre-Sarrailh C, Devaux JJ. Neuro-glial interactions at the nodes of Ranvier: implication in health and diseases. Front Cell Neurosci 2013;7:196.

20. Derfuss T, Linington C, Hohlfeld R, Meinl E. Axo-glial antigens as targets in multiple sclerosis: implications for axonal and grey matter injury. J Mol Med (Berl) 2010; 88:753-761.
21. Mathey EK, Derfuss T, Storch MK, et al. Neurofascin as a novel target for autoantibody-mediated axonal injury. J Exp Med 2007;204:2363-2372.

22. Howell OW, Palser A, Polito A, et al. Disruption of neurofascin localization reveals early changes preceding demyelination and remyelination in multiple sclerosis. Brain 2006;129:3173-3185.

23. Yamada H, Fredette B, Shitara K, et al. The brain chondroitin sulfate proteoglycan brevican associates with astrocytes ensheathing cerebellar glomeruli and inhibits neurite outgrowth from granule neurons. J Neurosci 1997;17: 7784-7795.

24. Vilijn MH, Das B, Kessler JA, Fricker LD. Cultured astrocytes and neurons synthesize and secrete carboxypeptidase E, a neuropeptide-processing enzyme. J Neurochem 1989;53:1487-1493.

25. Ozkaynak E, Abello G, Jaegle M, et al. Adam22 is a major neuronal receptor for Lgi4-mediated Schwann cell signaling. J Neurosci 2010;30:3857-3864.

26. Scarisbrick IA, Yoon H, Panos M, et al. Kallikrein 6 regulates early CNS demyelination in a viral model of multiple sclerosis. Brain Pathol 2012;22:709-722.

27. Hebb AL, Bhan V, Wishart AD, Moore CS, Robertson GS. Human kallikrein 6 cerebrospinal levels are elevated in multiple sclerosis. Curr Drug Discov Technol 2010;7:137-140.

28. Latour S, Tanaka H, Demeure C, et al. Bidirectional negative regulation of human $\mathrm{T}$ and dendritic cells by CD47 and its cognate receptor signal-regulator proteinalpha: down-regulation of IL-12 responsiveness and inhibition of dendritic cell activation. J Immunol 2001;167: 2547-2554.

29. O'Donnell LC, Druhan LJ, Avalos BR. Molecular characterization and expression analysis of leucine-rich alpha2glycoprotein, a novel marker of granulocytic differentiation. J Leukoc Biol 2002;72:478-485.

30. Chang KH, Tseng MY, Ro LS, et al. Analyses of haptoglobin level in the cerebrospinal fluid and serum of patients with neuromyelitis optica and multiple sclerosis. Clin Chim Acta 2013;417:26-30.

31. Chung LP, Reid KB. Structural and functional studies on C4b-binding protein, a regulatory component of the human complement system. Biosci Rep 1985;5:855-865.

32. Kurne A, Sayat G, Aydin OF, et al. Lack of association of the CD14/C-159T polymorphism with susceptibility and progression parameters in Turkish multiple sclerosis patients. J Neuroimmunol 2012;250:83-86.

33. Kitchens RL, Thompson PA. Modulatory effects of sCD14 and LBP on LPS-host cell interactions. J Endotoxin Res 2005;11:225-229.

34. Huh JR, Foe I, Muro I, et al. The Drosophila inhibitor of apoptosis (IAP) DIAP2 is dispensable for cell survival, required for the innate immune response to gram-negative bacterial infection, and can be negatively regulated by the reaper/hid/grim family of IAP-binding apoptosis inducers. J Biol Chem 2007;282:2056-2068.

35. Jacobsen KT, Iverfeldt K. Amyloid precursor protein and its homologues: a family of proteolysis-dependent receptors. Cell Mol Life Sci 2009;66:2299-2318.

36. Koshimizu H, Senatorov V, Loh YP, Gozes I. Neuroprotective protein and carboxypeptidase E. J Mol Neurosci 2009;39:1-8.

37. Schafer M, Brauer AU, Savaskan NE, Rathjen FG, Brummendorf T. Neurotractin/kilon promotes neurite 
outgrowth and is expressed on reactive astrocytes after entorhinal cortex lesion. Mol Cell Neurosci 2005;29: 580-590.

38. Stoop MP, Coulier L, Rosenling T, et al. Quantitative proteomics and metabolomics analysis of normal human cerebrospinal fluid samples. Mol Cell Proteomics 2010;9: 2063-2075.
39. Pepe G, Chimienti G, Liuzzi GM, et al. Lipoprotein(a) in the cerebrospinal fluid of neurological patients with bloodcerebrospinal fluid barrier dysfunction. Clin Chem 2006; 52:2043-2048.

40. Nielsen MJ, Petersen SV, Jacobsen C, et al. Haptoglobinrelated protein is a high-affinity hemoglobin-binding plasma protein. Blood 2006;108:2846-2849. 


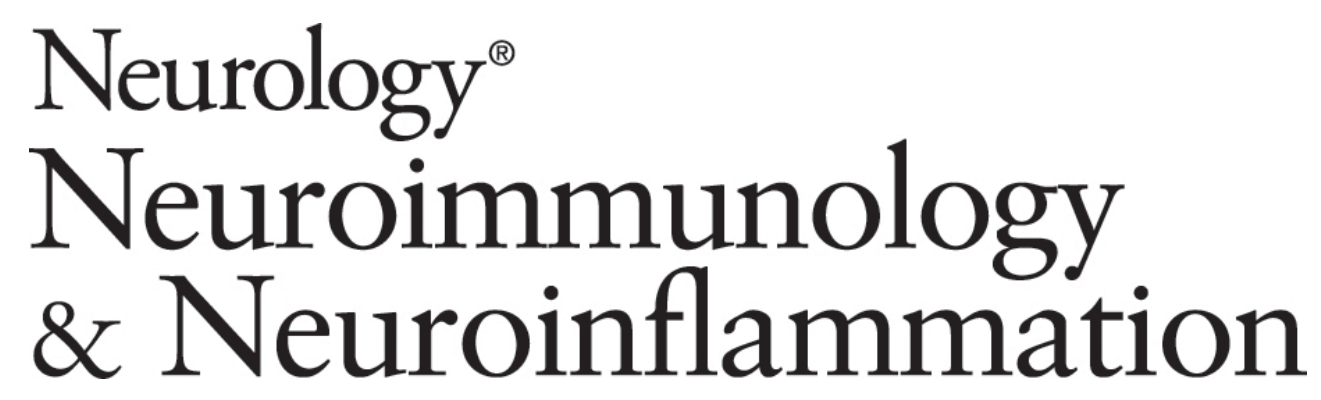

Gray matter-related proteins are associated with childhood-onset multiple sclerosis

Vaibhav Singh, E. Daniëlle van Pelt, Marcel P. Stoop, et al.

Neurol Neuroimmunol Neuroinflamm 2015;2;

DOI 10.1212/NXI.0000000000000155

This information is current as of September 24, 2015

Neurol Neuroimmunol Neuroinflamm is an official journal of the American Academy of Neurology.

Published since April 2014, it is an open-access, online-only, continuous publication journal. Copyright $\odot$ 2015 American Academy of Neurology. All rights reserved. Online ISSN: 2332-7812.

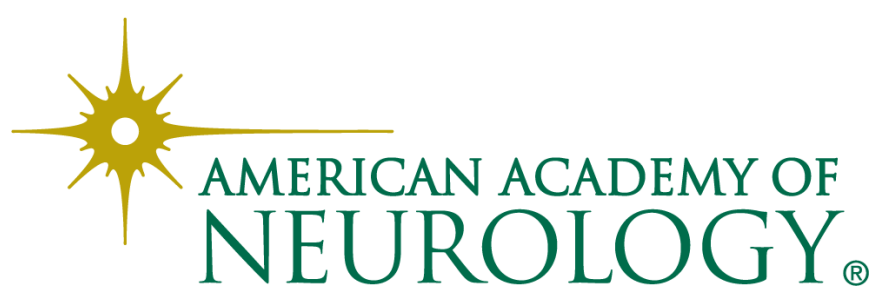




\section{Updated Information \&} Services

\section{Supplementary Material}

\section{References}

Citations

Subspecialty Collections

Permissions \& Licensing

Reprints including high resolution figures, can be found at: http://nn.neurology.org/content/2/5/e155.full.html

Supplementary material can be found at: http://nn.neurology.org/content/suppl/2015/09/24/2.5.e155.DC1

This article cites 39 articles, 10 of which you can access for free at: http://nn.neurology.org/content/2/5/e155.full.html\#\#ref-list-1

This article has been cited by 1 HighWire-hosted articles: http://nn.neurology.org/content/2/5/e155.full.html\#\#otherarticles

This article, along with others on similar topics, appears in the following collection(s):

\section{Acute disseminated encephalomyelitis}

http://nn.neurology.org//cgi/collection/acute_disseminated_encephalo myelitis

All Pediatric

http://nn.neurology.org//cgi/collection/all_pediatric

Multiple sclerosis

http://nn.neurology.org//cgi/collection/multiple_sclerosis

Information about reproducing this article in parts (figures,tables) or in its entirety can be found online at:

http://nn.neurology.org/misc/about.xhtml\#permissions

Information about ordering reprints can be found online: http://nn.neurology.org/misc/addir.xhtml\#reprintsus

Neurol Neuroimmunol Neuroinflamm is an official journal of the American Academy of Neurology.

Published since April 2014, it is an open-access, online-only, continuous publication journal. Copyright $\odot$ 2015 American Academy of Neurology. All rights reserved. Online ISSN: 2332-7812.

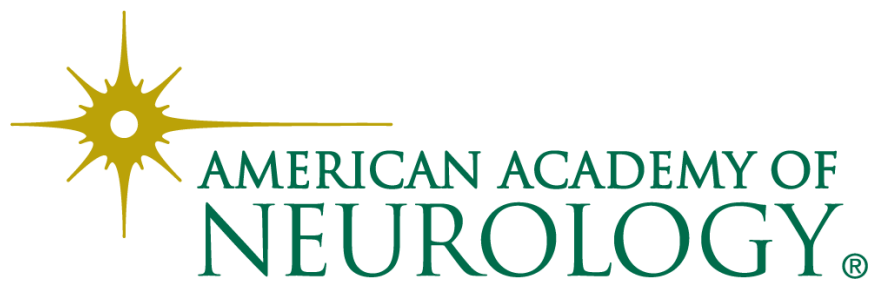

